\title{
Clinicians' views on parental involvement in the treatment of adolescent anorexia nervosa
}

\author{
Debbie Plath ${ }^{\mathrm{a}}$, Lauren T. Williams ${ }^{\mathrm{b}}$, and Cath Wood ${ }^{\mathrm{a}}$ \\ aSchool of Humanities and Social Sciences, University of Newcastle, Newcastle, New South Wales, \\ Australia; ${ }^{b}$ School of Health Sciences, University of Newcastle, Newcastle, New South Wales, Australia
}

\begin{abstract}
A questionnaire and in-depth interviews with 20 allied health clinicians generated data on key aspects of family-based treatment for adolescent anorexia nervosa that enhance recovery, processes that engage parents in treatment, and how and why clinicians modify or adapt the manualized Maudsley Family Based Treatment model. Findings indicate that clinicians support key principles in the Maudsley model, but that the approach is not implemented in the full, manualized form. Rather, aspects are integrated with clinicians' own clinical judgements based on assessment of the needs and capacities of families, cultural appropriateness, impact on family dynamics, and gains during early treatment.
\end{abstract}

\section{Introduction}

There is considerable agreement on the value of family therapy interventions in the treatment of adolescent anorexia nervosa (AN). Family based therapy is widely used in clinical settings and is the mode of treatment most often tested by randomized controlled trials (Lock, 2011). Reviews of clinical trials of treatments for adolescent AN in community settings indicate that family therapy is effective in the treatment of adolescent AN, and that other types of interventions have less high quality research for comparison (Bulik, Berkman, Brownley, Sedway, \& Lohr, 2007; Cook-Darzens et al., 2008; Fisher, Hetrick, \& Rushford, 2010; Gowers et al., 2007; Keel \& Haedt, 2008; Lock, 2011). The Maudsley Family Based Treatment model for adolescent AN (referred to throughout the article as Maudsley), in particular, has undergone numerous clinical trials and has a strong evidence base (Keel \& Haedt, 2008).

The Maudsley model requires a sequential approach to family treatment, aligned with stages of recovery from adolescent AN and supported by a detailed manual for implementation (Lock \& Le Grange, 2013). Conjoint

CONTACT Debbie Plath debbieplath@optusnet.com.au E Debbie Plath Consulting, 20 The Terrace, The Hill, 2300 NSW, Australia.

Debbie Plath is now at Debbie Plath Consulting, Newcastle, New South Wales, Australia. Lauren T. Williams is currently affiliated with the School of Allied Health Sciences, Griffith University, Southport, Queensland, Australia. Cath Wood is currently affiliated with the Division of Allied Health, Hunter New England Mental Health, Waratah, New South Wales, Australia. 
family work is an integral component of Maudsley, with family members who reside in the home of a young person regarded as resources in treatment. Family commitment to and involvement in treatment is fundamental to the intervention. For example, interventions include a family meal that involves all family members. Parents are instructed to bring a meal into treatment, to feed their starving child and to feed one more mouth full than their child is prepared to take. Each family member has a role to play in this session; a parent encourages their child to eat, and siblings provide uncritical support and empathy (Lock \& Le Grange, 2013). Whilst the evidence for Maudsley is strong, it is not definitive that it is the most effective treatment for mood improvement and healthy weight gain for all adolescents with AN. Maudsley has been found to work for around two thirds of adolescents with AN who remain for the duration of clinical trials (Le Grange \& Lock, 2005). The dropout rate from clinical trials of adolescent treatments for AN is $10 \%$ to 20\% (Eisler et al., 2000; Lock, Agras, Bryson, \& Kraemer, 2005; Lock, Couturier, Bryson, \& Agras, 2006; Szmukler, Eisler, Russell, \& Dare, 1985). This raises questions regarding how services offering Maudsley treatment can respond to around $50 \%$ of adolescents and families that do not engage with or respond well to Maudsley and whether alternative treatment approaches may suit some families better.

Gathering parents' and clinicians' views on parents' experiences of taking part in family treatment for adolescent $\mathrm{AN}$ can begin to inform answers to these questions. Research into parents' perspectives on the acceptability, effectiveness and usefulness of Maudsley family treatment has offered insights for program implementation (Krautter \& Lock, 2004; Rhodes, Baillee, Brown, \& Madden, 2008; Rhodes, Brown, Baillee, \& Madden, 2005). Connecting with parents' experiences of treatment is important because parental self-efficacy is recognized as a predictor of positive outcomes for adolescents being treated for AN (Stillar et al., 2016). Understanding the experiences of parents caring for someone with an eating disorder is also important because the high levels of psychological distress and burden can serve to maintain the symptoms and reduce the family's ability to use adaptive mechanisms to help in treatment (Eisler, 2005; Ma, 2011; Treasure et al., 2007; Zabala, MacDonald, \& Treasure, 2009). Providing a service that is responsive to parents' priorities and concerns, supportive of parents facing emotional and psychological distress and culturally appropriate, is better placed to retain adolescents and their families in treatment (CotteeLane, Pistrang, \& Bryant-Waugh, 2004).

Adapting standardized treatments in response to parental requests is, however, a potentially risky path to take. As with all evidence-based, therapeutic interventions, outcomes are associated with fidelity in the implementation of standardized treatment protocols, in comparable contexts, with participants 
with similar characteristics. This, however, may not be possible or desirable in the real world of mental health service provision to vulnerable children and families. A range of organizational, client, and clinician factors can influence compliance with manualized treatments (Aarons \& Palinkas, 2007). Based on bodies of professional knowledge, practice wisdom, and assessments of individual cases, clinicians make decisions about appropriate principles and processes for treatment. In the field of family treatment for $\mathrm{AN}$, a better understanding of how and why clinicians deviate from standardized treatments can highlight areas for future research and issues for attention in practice.

The research reported here is part of a larger study of the processes that optimize parents'/carers' experiences of treatment for adolescent AN. Through semi-structured interviews and survey questionnaires, data were generated from the perspectives of both parents of adolescents who have undergone treatment and clinicians providing treatment for adolescent AN in a regional public health service in New South Wales (NSW), Australia. The component of the study reported here examined clinicians' views on the processes that optimize parents'/carers' experiences of treatment for adolescent AN. It was anticipated that practices to engage and support parents may, at times, be at odds with the procedures and processes stipulated in the manualized Maudsley model. Clinicians' views on parents' experiences and the presenting tensions with manualized treatment were examined through the research. Clinicians drew on their own experiences of providing treatment and contributed their views on:

(1) Key aspects of family-based community treatments for adolescent AN that enhance recovery;

(2) Processes that engage parents in treatment; and

(3) How and why clinicians modify or adapt the Maudsley Family Based Treatment model.

\section{Methods}

\section{Participants}

Clinicians who participated in the study were employed in the public Child and Adolescent Mental Health Service (CAMHS) located in a diverse health region of NSW, Australia servicing a population of around 900,000 in metropolitan, regional, and rural settings. Clinicians provide interventions to children and young people presenting with a range of moderate to severe mental health conditions, including eating disorders. Family-based therapeutic approaches have been adopted in the service as the most appropriate for AN. This includes Maudsley Family Based Treatment and other family therapy and family-centered approaches to practice such as systemic and 
narrative family therapy. There is acknowledgement within CAMHS that whilst Maudsley is recognized as having a good evidence base, it may not be suited to all clients. Clinicians are supported by the service to undertake Maudsley training which is delivered from a specialist Maudsley center in Sydney and includes individual supervision from Sydney and peer supervision locally. Other clinicians are trained in other forms of family therapy and individual treatment.

Clinical leaders in the service were asked to identify those clinicians providing family-based therapy for adolescent AN. Invitations to take part in the research were distributed to these clinicians. Thirty clinicians from four rural, remote and urban sites in the geographic region were invited to participate. The professional disciplines of the clinicians comprised psychiatry, social work, psychology, dietetics, nursing, occupational therapy, and Aboriginal counselling. Invitation packs sent to potential participants included information on the research, a survey questionnaire, and a consent form to participate in a follow-up semi-structured interview. All procedures, measures, and documentation were approved in advance by the Hunter New England Health Human Research Ethics Committee.

\section{Measures}

A written, self-administered survey questionnaire was used to measure clinicians' views on the level of importance of key components of the Maudsley treatment approach and to gather descriptive data on clinician characteristics and treatment modes. The questionnaire was based on the Outcome Effective Scale (OES) used in a Stanford University California study of parent and child satisfaction with Maudsley manualized treatment for AN (Krautter \& Lock, 2004). With author permission, the questionnaire was adapted for use with clinicians. The adapted scale comprised a list of ten key aspects of the Maudsley treatment approach, which clinicians were asked to rank on a 5 point Likert scale from not at all important to extremely important. These key treatment principles comprised: relationship between clinician and parent; provision of information on the illness; including parent actively in treatment; separating illness from the child; assigning parents the task of decision making about food in the early stage of illness; handing decisions about food back to child when healthy weight reached; teaching parents how to stand up to AN; treating adolescent's issues once healthy weight attained; building parental capacity to support their child; and active parenting to assist recovery. Three open questions sought comment on helpful and unhelpful aspects of treatment and the common experiences of parenting a child with AN. Data on clinician characteristics and types of treatment provided were also gathered in the survey (gender, professional discipline, level of education, employment status, cultural background, experience with family based 
treatment for AN, training in Maudsley treatment, use of Maudsley and/or other types of family or individual treatment).

Building on data generated by the survey, in-depth semi-structured interviews were designed to elicit detailed, qualitative information on clinicians' experiences of and views on treatment. Clinicians were offered the choice of either face to face or telephone interviews. Interview questions were broad and open with the aims of facilitating reflection on practice and generating detailed responses from clinicians on their experiences of treatment for AN. One of the authors conducted all interviews. A flexible approach was taken, allowing clinicians to elaborate on the issues they regarded as central, whilst also ensuring that all pre-determined questions in the interview schedule were addressed. The interview schedule comprised questions about clinicians' perceptions of: parents' experiences of treatment; the range of values and beliefs about food and eating that present in treatment; how parents in treatment perceive their own parenting; aspects of treatment that are helpful and unhelpful for parents; educational needs of parents; and, parents' experiences of having an adolescent with AN. A list of prompting sub-questions was used by the interviewer to facilitate further reflection and explanation. Participants were also asked to provide specific examples from their own practice experiences. All interviews were digitally audio-recorded with participant consent and fully transcribed. Participants were offered a copy of their transcription for correction and additions.

A second follow-up interview was held with clinicians to examine in more detail the circumstances in which modifications were made to manualized treatments, the nature of modifications made and the rationale for variations.

\section{Data analysis}

The data set generated from scanned teleform survey questionnaires was imported into the Statistical Software Package for Social Science (SPSS version 18). SPSS was used to generate descriptive statistics (frequencies and percentages). Respondents were assigned to one of two groups: those who reported providing Maudsley manualized treatment and those who did not. The group sizes were, however, too small for further useful statistical analysis and only descriptive statistics are reported. Content analysis was used to analyze data from the open-ended survey questions, with responses being grouped thematically (Marshall \& Rossman, 2006).

Data from semi-structured interviews were de-identified and analyzed using Interpretative Phenomenological Analysis (IPA) (Smith, Flowers, \& Larkin, 2009), aided by the software package QSR-NVivo 9. The aim of IPA analysis is to discover the complexity of meanings relating to a given phenomenon. This involved gaining a detailed familiarity with the interview transcripts through reading and re-reading, accompanied by a process of reflexive thinking and interpretation. Initially meaning units were marked 
and comments assigned for each unit by one of the authors. Concise phrases or titles for emerging themes, reflecting the essential nature of transcript contents, were then produced. Where similar themes emerged, the theme titles were combined. An iterative research team review process resulted in more analytical ordering, where connections, groups, and sub-themes were identified. As each clustering theme emerged, it was checked against the transcripts to ensure the connections applied to the primary source material. Respect was given to both the convergence and divergence of meanings in the data. New themes and alternative views were noted, as well as confirming patterns. The use of key word extraction in QSR- NVivo 9 further assisted a thorough consideration of instances of each theme in the transcripts. The next phase entailed producing a table of themes which captured, as best as possible, clinicians' views on the topic. Clusters of themes were named to depict superordinate themes. The table of themes offers a concise overview of clinicians' views and experiences, and also serves as a narrative argument supported by verbatim extracts from the transcripts. A reductionist approach was avoided by ensuring that supporting quotes, long transcript extracts, narratives, and contextual features supported and remained linked to the final summary. Pseudonyms are used in the presentation of findings.

\section{Results}

Twenty clinicians providing family-based therapy for adolescent AN completed the survey and also took part in face to face interviews of 45 to 90 minutes duration. Follow-up interviews of up to 45 minutes duration were conducted with 16 of these clinicians.

\section{Participant characteristics}

The 20 clinicians represent $67 \%$ of the 30 clinicians providing family-based treatment for adolescent AN in the health area at the time of the research. A profile of the characteristics of the clinicians is provided in Table 1. The majority of the clinicians were White, well-educated women. Although a range of professions was represented, the most frequent was psychology $(40 \%)$. More than half of the sample was employed full-time and more than half had more than 3 years of experience with family based treatment for AN. Of the 20 clinicians, 14 were trained in Maudsley Family Based Treatment and reported using this model to treat adolescent AN.

\section{Clinicians' support for key treatment principles}

The survey results on clinicians' ratings of importance of key aspects of treatment are reported in Table 2. The results show that clinicians attach a high level of 
Table 1. Characteristics of participant clinicians $(n=20)$.

\begin{tabular}{lc}
\hline Demographic characteristic & $\%(n)$ \\
\hline Gender & \\
Female & $75(15)$ \\
Male & $25(5)$ \\
Profession & \\
Psychologist & $40(8)$ \\
Dietitian & $20(4)$ \\
Social worker & $10(2)$ \\
Psychiatrist & $10(2)$ \\
Nurse & $10(2)$ \\
Aboriginal counsellor & $5(1)$ \\
Occupational therapist & $5(1)$ \\
Highest education & \\
Postgraduate qualifications & $65(13)$ \\
Undergraduate degree & $35(7)$ \\
Employment status & \\
Full-time & $60(12)$ \\
Part-time & $35(7)$ \\
Casual & $5(1)$ \\
Aboriginal or Torres Strait Islander & \\
No & $95(19)$ \\
Yes & $5(1)$ \\
Australian born & \\
Yes & $80(16)$ \\
No & $20(4)$ \\
Parents born overseas & \\
No & $70(14)$ \\
Yes & $30(6)$ \\
Employment in the service & \\
$>3$ years & $60(12)$ \\
$<3$ years & $40(8)$ \\
Experience with family-based treatment for AN & \\
$>3$ years & $55(11)$ \\
< 3 years & $45(9)$ \\
Trained as Maudsley family therapist & \\
Yes & $70(14)$ \\
No & $30(6)$ \\
\hline & \\
&
\end{tabular}

importance to each of the principles of the Maudsley treatment model. This was the case both for those trained as Maudsley therapists and those who were not. Whilst the small sample size did not support statistical tests of significance, the data in the table show alignment between Maudsley and non-Maudsley clinicians in terms of what they perceive as important in treatment. Nine out of the ten aspects of treatment were ranked as "very important" by $90 \%$ or more of clinicians. "Assigning the task of parental refeeding" was the only aspect of treatment with somewhat less support from both groups, being ranked as "very important" by $70 \%$ of clinicians. These findings indicate that clinicians place high value on engaging and building relationships with parents, involving them in the treatment process, and building their capacities through the provision of information, support, and guidance. The responses to open questions indicated that clinicians regarded psycho-education, externalization, systemic family work, and enhancing parental capacities as the most helpful aspects of treatment, whilst also identifying 
Table 2. Maudsley-trained and non-Maudsley clinicians' ratings of importance of treatment principles.

\begin{tabular}{|c|c|c|c|}
\hline Aspect of treatment & $\begin{array}{c}\text { Maudsley }(n=14) \\
\%(n)\end{array}$ & $\begin{array}{c}\text { Non-Maudsley }(n=6) \\
\%(n)\end{array}$ & $\begin{array}{c}\text { Total }(n=20) \\
\%(n)\end{array}$ \\
\hline \multicolumn{4}{|c|}{ Relationship between parent and therapist } \\
\hline Very important & $92.9(13)$ & $100(6)$ & 95 (19) \\
\hline Reasonably important & $7.1(1)$ & $0(0)$ & $5(1)$ \\
\hline Not important & $0(0)$ & $0(0)$ & $0(0)$ \\
\hline \multicolumn{4}{|c|}{ Providing information to parents } \\
\hline Very important & $92.9(13)$ & $83.3(5)$ & $90(18)$ \\
\hline Reasonably important & $7.1(1)$ & $16.7(1)$ & $10(2)$ \\
\hline Not important & $0(0)$ & $0(0)$ & $0(0)$ \\
\hline \multicolumn{4}{|c|}{ Including parent actively in treatment } \\
\hline Very important & $100(14)$ & $100(6)$ & $100(20)$ \\
\hline Reasonably important & $0(0)$ & $0(0)$ & $0(0)$ \\
\hline Not important & $0(0)$ & $0(0)$ & $0(0)$ \\
\hline \multicolumn{4}{|c|}{ Separation of illness from child } \\
\hline Very important & $100(14)$ & $100(6)$ & $100(20)$ \\
\hline Reasonably important & $0(0)$ & $0(0)$ & $0(0)$ \\
\hline Not important & $0(0)$ & $0(0)$ & $0(0)$ \\
\hline \multicolumn{4}{|c|}{ Assigning the task of parental refeeding } \\
\hline Very important & $71.4(10)$ & $66.7(4)$ & $70(14)$ \\
\hline Reasonably important & $21.4(3)$ & $33.3(2)$ & $25(5)$ \\
\hline Not important & $7.1(1)$ & $0(0)$ & $5(1)$ \\
\hline \multicolumn{4}{|c|}{ Handing back decisions to child once healthy } \\
\hline Very important & $85.7(12)$ & $100(6)$ & $90(18)$ \\
\hline Reasonably important & $14.3(2)$ & $0(0)$ & $10(2)$ \\
\hline Not important & $0(0)$ & $0(0)$ & $0(0)$ \\
\hline \multicolumn{4}{|c|}{ Teaching how to stand up to AN } \\
\hline Very important & $100(14)$ & $83.3(5)$ & 95 (19) \\
\hline Reasonably important & $0(0)$ & $16.7(1)$ & $5(1)$ \\
\hline Not important & $0(0)$ & $0(0)$ & $0(0)$ \\
\hline \multicolumn{4}{|c|}{ Treat adolescents' issues once child is healthy } \\
\hline Very important & $92.9(13)$ & $100(6)$ & $95(19)$ \\
\hline Reasonably important & $7.1(1)$ & $0(0)$ & $5(1)$ \\
\hline Not important & $0(0)$ & $0(0)$ & $0(0)$ \\
\hline \multicolumn{4}{|l|}{ Enhancing parental ability } \\
\hline Very important & $92.9(13)$ & $100(6)$ & $95(19)$ \\
\hline Reasonably important & $7.1(1)$ & $0(0)$ & $5(1)$ \\
\hline Not important & $0(0)$ & $0(0)$ & $0(0)$ \\
\hline \multicolumn{4}{|c|}{ Active parenting in treating $\mathrm{AN}$} \\
\hline Very important & $92.9(13)$ & $83.3(5)$ & $90(18)$ \\
\hline Reasonably important & $7.1(1)$ & $16.7(1)$ & $10(2)$ \\
\hline Not important & $0(0)$ & $0(0)$ & $0(0)$ \\
\hline
\end{tabular}

poor engagement with parents, lack of attention to the psychological wellbeing of parents, and inconsistent treatment approaches as unhelpful to parents. Findings from the in-depth interviews provided further insights into the complexities and challenges associated with implementing these principles in practice.

Five broad themes relating to clinicians' views on parental involvement in AN treatment emerged from the interviews: professional judgement and choice; realizing the challenges in treating AN; making sense of parental vulnerability in treatment; making sense of parents' experiences outside of treatment; and 
insights into parents' sense of self. Each of these themes is discussed in turn, with Table 3 providing a summary of themes and brief illustrative quotes.

\section{Professional judgement and choice}

Clinicians spoke about making treatment decisions and how they needed to balance the assessed needs, responsiveness, and capacities of families

Table 3. Themes and subthemes from clinician interviews.

\begin{tabular}{|c|c|c|}
\hline Themes & Subthemes & Key quotes \\
\hline \multirow[t]{5}{*}{$\begin{array}{l}\text { Professional judgement and } \\
\text { choice }\end{array}$} & $\begin{array}{r}\text { Considering } \\
\text { Maudsley }\end{array}$ & $\begin{array}{l}\text {... in the manual it says we don't know who } \\
\text { Maudsley is going to work for and who it's not. }\end{array}$ \\
\hline & $\begin{array}{l}\text { A structured } \\
\text { approach to } \\
\text { treatment }\end{array}$ & $\begin{array}{l}\text {... important if cognitively, someone has been } \\
\text { severely struggling with anorexia. }\end{array}$ \\
\hline & Adapting Maudsley & $\begin{array}{l}\ldots \text { it wasn't the purist Maudsley at all. We adapted } \\
\text { it to suit them better. }\end{array}$ \\
\hline & $\begin{array}{l}\text { Treatment driven } \\
\text { practice }\end{array}$ & $\begin{array}{l}\text {.. with eating disorders you start with the } \\
\text { treatment first and then learn about the family. }\end{array}$ \\
\hline & $\begin{array}{l}\text { Power and } \\
\text { oppression }\end{array}$ & $\begin{array}{l}\text {... the father was saying you must do as I say or } \\
\text { else. }\end{array}$ \\
\hline \multirow[t]{5}{*}{$\begin{array}{l}\text { Realizing the challenges in } \\
\text { treating AN }\end{array}$} & $\begin{array}{l}\text { Shaping of initial } \\
\text { experiences }\end{array}$ & $\begin{array}{l}\text { Parents may never have had experiences with } \\
\text { mental health; parents need time to understand } \\
\text { what that means. }\end{array}$ \\
\hline & Cohesive team & $\begin{array}{l}\text {... she'd got a handle on managing different } \\
\text { scenarios through multidisciplinary input. }\end{array}$ \\
\hline & $\begin{array}{l}\text { Challenges in } \\
\text { treatment }\end{array}$ & $\begin{array}{l}\ldots \text { it's their responsibility in treatment that } \\
\text { becomes challenging. }\end{array}$ \\
\hline & Searching for more & $\begin{array}{l}\text { Sometimes parents just feel terribly frustrated that } \\
\text { we don't just tell them what to do, like we're } \\
\text { holding a big secret or something. }\end{array}$ \\
\hline & $\begin{array}{l}\text { Connecting with } \\
\text { beliefs and } \\
\text { values }\end{array}$ & $\begin{array}{l}\text { Part of the treatment that we offered with this } \\
\text { family was to understand how values attached to } \\
\text { their culture impacted upon re-nourishing. }\end{array}$ \\
\hline \multirow[t]{2}{*}{$\begin{array}{l}\text { Making sense of parental } \\
\text { vulnerability in treatment }\end{array}$} & $\begin{array}{l}\text { Emotional } \\
\text { vulnerability }\end{array}$ & $\begin{array}{l}\text { I think it means a mixture of relief and a sense of } \\
\text { just putting themselves on the line. }\end{array}$ \\
\hline & A lifeline & $\begin{array}{l}\text {... parents say "can you figure out how to parent } \\
\text { this child because I don't think I know how to } \\
\text { parent them anymore." }\end{array}$ \\
\hline \multirow[t]{2}{*}{$\begin{array}{l}\text { Making sense of parents' } \\
\text { experiences outside of } \\
\text { treatment }\end{array}$} & Disempowerment & $\begin{array}{l}\text { Anorexia nervosa confronts parents with their own } \\
\text { inadequacy or self-perceived inadequacies about } \\
\text { their parenting. It takes something away from them. }\end{array}$ \\
\hline & Shame & $\begin{array}{l}\text { There's a shame in saying, "well I need to monitor } \\
\text { her because she has an eating disorder." }\end{array}$ \\
\hline \multirow[t]{3}{*}{$\begin{array}{l}\text { Insights into parents' sense of } \\
\text { self }\end{array}$} & $\begin{array}{l}\text { Questioning } \\
\text { themselves }\end{array}$ & $\begin{array}{l}\text {... question how they feel about themself as a } \\
\text { parent. }\end{array}$ \\
\hline & Loss & They've lost their child to something else. \\
\hline & $\begin{array}{c}\text { Meaning in } \\
\text { recovery }\end{array}$ & Strengthening the parenting relationship. \\
\hline
\end{tabular}


with the requirements of standardized procedures for evidence-based treatment. All of the 14 participants identifying as using Maudsley said that they generally do not strictly adhere to the manual. In their professional judgement, adherence to components in the manual could jeopardize parents engagement with treatment or could convey a lack of responsiveness to parents needs in certain cases. Clinicians who identified as non-Maudsley did not describe significantly different approaches to practice; rather, they reported practices very similar to the Maudsley trained clinicians. All clinicians utilized key principles of manualized Maudsley in their treatment, whilst not following strictly the manualized protocols. Clinicians adapted manualized Maudsley either to meet the assessed needs of the families or to address power imbalances in the therapeutic relationship that were counterproductive in treatment. Clinicians who worked with Aboriginal families diverged from the Maudsley or Maudsley-type treatment, choosing instead to work with kinship networks, values, and beliefs as more culturally respectful and appropriate. Five sub-themes were derived from clinicians' comments on professional judgements and decision making in treatment.

\section{Considering Maudsley}

Clinicians recognize that whilst Maudsley has evidence of success, it is not suited to everyone. On the basis of their assessments of the needs and capabilities of parents, clinicians decide on the most appropriate treatment, with varying degrees of input from parents:

...with Maudsley, the whole emphasis is they'd take the responsibility for feeding their child and in the case I'm thinking of, the parents refused it. Mum just wasn't coping and there was just too much for mum to do, so we had to change what we offered. (Ann)

\section{Structured approach to treatment}

Clinicians conceptualized treatment they offered as a staged approach and referred to it as "structured treatment" rather than "manualized." The sequential phases of treatment described by clinicians loosely corresponded to phases in Maudsley, yet there were deviations from procedures in the manual, in particular, avoidance of the family meal. This formed the basis of what appears to be a Maudsley-type approach to treatment that offered a framework, rather than a manual, for treatment. Clinicians tended to assess parental capacity in each stage of treatment which informed decisions of whether to proceed with or further adapt the manualized Maudsley approach. There was general agreement amongst clinicians, that structured treatment was the path to follow, because it provided a framework for assessment and for dealing with the 
physical and cognitive complexities associated with starvation. Decisions about the type and format of family-based treatment offered were made by balancing family capacity with the risk factors associated with the illness:

The structure associated with Maudsley could be seen to provide containment. If families really want that clarity, want to know what their next step is and really want a more rigid structure then I think that can be really helpful. (Katrina)

\section{Adapting Maudsley}

Adaptations to Maudsley tended to occur in circumstances where parents were unable to re-nourish their child in the manner proposed by manualized Maudsley treatment or where principles that guide practice using Maudsley reinforced abusive patterns within the family. Stages of manualized treatment were deconstructed and enhanced to meet family need or capacity. Examples included providing separated family therapy after the first session, moving away from rigid behavioral strategies for refeeding in stage one in circumstances where the young person had experienced abuse within the family, and involving culturally appropriate extended family members who reside outside the home to assist with re-nourishment:

I don't think anyone's been a purist in their delivery of Maudsley. ... Where it's more of a straightforward family, where the eating disorder pops up; you do treatment and eating gets back on track. That's where we would do more of structured Maudsley and not take little, um excursions to do some other interventions. Where it's more complicated, that's where we've noticed we've had to do some other stuff; as an adjunct to the Maudsley treatment. (Monica)

\section{Treatment driven practice}

Despite no clinician saying they strictly adhered to manualized Maudsley, knowledge derived from scientific research was valued by clinicians. Participants spoke of how evidence-based treatment models informed and drove clinical practice for eating disorders in the service. These treatment models were regarded as privileged, valued knowledge within the service, whilst the knowledge derived from professional assessment of families and critical reflection on practice experiences was less well regarded:

It's a very "should" thing. You've always got to argue why you wouldn't do Maudsley. I think if I just said I was going to do some work with a family with an eating disorder, the Maudsley clinicians would say "so why aren't you doing Maudsley?" and I would say "yes well, that's because I haven't met the family yet!" There's almost the assumption now that you go in ready to do Maudsley. That's the start point. (Jane) 


\section{Power and oppression}

Some clinicians commented that family-based treatment has the potential to further oppress families who already experience marginalization, by reinforcing systemic oppression in the treatment setting or in the family. The authority given to parents or to the clinician in manualized Maudsley or Maudsley-type treatment can mirror and reinforce societal inequalities in terms of ethnicity, gender, age, and education, or can exacerbate dominating or abusive relationships in the family. The need for flexibility and responsiveness to cultural differences was identified as important if progress in treatment is to be made.

If you come in with the Maudsley approach for an Indigenous family you probably wouldn't get many more than two sessions. It wouldn't work because it's again pushing the family and telling the family what they've got to do instead of giving them ideas or helping them through that process, so they can do it themselves. (Mick)

Uptight and White.... White people talk that gets in the way of maintaining engagement with Aboriginal families. (Margaret)

\section{Realizing the challenges in treating $A N$}

Clinicians drew on their own experiences of what parents found most helpful and unhelpful in addressing the challenges of AN. Five sub-themes emerged.

\section{Shaping initial experiences}

Expressing empathy for the emotional state of parents at commencement of treatment was identified by some clinicians as the first and the most important step if parents, and consequently the adolescent with $\mathrm{AN}$, are to be engaged with and committed to treatment. Others viewed early activation of parents in treatment as the most important first step:

I think that parents come to us in a great deal of distress and as clinicians we often fall into the trap of assuming that parents will understand what we're about to work on with their children ... I don't know that we actually spend enough time acknowledging that these are people in crisis and distress and they're not actually listening very well; so they don't pick up on what's happening. (Jane)

\section{Cohesive teamwork}

In helping parents reclaim authority and confidence, most clinicians promoted parents and clinicians working together as a team to identify challenges and determine strategies to counter the illness-driven behavior at home. Clinicians thought that parents' experiences of a multidisciplinary team approach to treatment created opportunities for differing perspectives on most aspects of care. This team approach to promoting active parenting was adopted by both Maudsley and non-Maudsley clinicians. Clinicians said that with time parents 
can recognize their potency as active agents in recovery and "...feel like part of a team we are all committed; that sense of we're in this with you" (Mandy).

\section{Challenges of treatment}

As well as facing the challenges of dealing with a child with AN, many clinicians recognized that parents find what is demanded of them emotionally, intellectually, and logistically in treatment burdensome and challenging. The momentum in treatment was also seen to challenge parents' sense of agency:

I think some families may potentially describe treatments provided as unrealistic for them; very difficult for them and probably feel that they don't have an understanding of why treatments would be the way that they are and why we would require the level of family commitment and involvement that we do. (Katrina)

It's their responsibility in treatment that becomes challenging; having to manage the eating disorder twenty-four hours a day and then having to come back into therapy and go through what's happened each day; the times where things have worked. Facing it head on and realistically that's what therapy does. It gets you to really look at what's happened in much greater detail than what you ever would if you were not going through that process. (Carla)

All of the parents that I recall have made comments about the frequency in which they have to attend appointments and the difficulty in finding the time and juggling, say work commitments and the kids with school. (Andrew)

\section{Searching for more}

Clinicians described how parents often sought direction, information, explanations, and solutions from them. Clinicians expressed discomfort when they were unable to meet the requests of desperate parents either because it was beyond their capacity to deliver what was wanted or because the therapeutic approach entails reflective and circular questioning that prompts families to take control of the situation at home. Clinicians sensed at times that parents thought they were holding things back from them:

Sometimes I feel that often parents just want us to tell them what to do instead of being a bit more reflective about what's going on in the home or at meal times ... I get the feeling that sometimes parents just feel terribly frustrated that we don't just tell them what to do, like we're holding a big secret or something. (Jessica)

... how do parents see us? I can think of some parents that felt we were really woefully inadequate, and said "you didn't fix the problem." (Margaret)

\section{Connecting with beliefs and values}

Some clinicians said that understanding parental cultural beliefs and values enhanced components of family-based treatment. They said that integrating values, beliefs, and associated patterns of behavior provided opportunities for 
new knowledge creation in treating adolescent $\mathrm{AN}$ that result in more respectful and helpful interventions for parents and better outcomes for the child:

... she was still in hospital but she could've been discharged except the parents said, "no please keep her in." They wanted her to stay because she could get an exemption from Ramadan. This girl thought it was really important, something she needed to do, so staying in hospital was very important to her parents or she'd be very torn. (Sue)

Before colonization happened we were very tall and slim built. ... So we did the simple things with the family like suggesting getting some kangaroo from the butchers or from out west. He and his family had a real a sense of pride. ... It was the pride about being Indigenous and wanting to connect and wanting to have the traditional food stuff and that's how I got them to come down to appointments. (Mick)

\section{Making sense of parental vulnerability in treatment}

Clinicians described the parents as vulnerable when they present with their child and discussed how treatment can both exacerbate and alleviate this vulnerability. Two subthemes were identified: emotional vulnerability and a lifeline.

\section{Emotional vulnerability}

Clinicians referred to treatment for adolescent $\mathrm{AN}$ as exposing the private domain of parenting, and discussed how the treatment process raised powerful emotions of fear, guilt and shame in parents:

... laying themselves bare to what they perceive as people judging their parenting skills, because having their child not eating, or vomiting and not getting sufficient nutrition is one of the key components, or perceived components, of bad parenting. (John)

\section{A lifeline}

Several clinicians identified that parents experienced a sense of relief and renewed hope in sharing the management of a complex illness with a team of clinicians. These clinicians saw themselves as active agents in the minds of parents, working together on new understandings to assist in the recovery process:

Some parents come when they are at the end of their tether and it's kind of humbling for them that they seek help. They feel they can't do it anymore and need someone else to help out ... sometimes it's a relief for them to have some support and back-up and somebody who can teach them about what's going on. (Nick)

At the outset of treatment it must be incredibly heart breaking to see your child diminish in front of your very eyes and feel unable to assist them. That changes throughout the course of treatment where more hope is generated, more of a sense of agency, a sense of being able to play a role in recovery and being seen as being resourceful towards the solution. (Monica) 


\section{Making sense of parents' experiences outside of treatment}

Beyond the realm of treatment, clinicians spoke about their insights into the lives of those parenting a child with AN. Two subthemes emerged.

\section{Disempowerment}

Clinicians spoke about the dwindling sense of self-efficacy for parents as they dealt with daily power struggles in a battle with an illness that attacks the core of parenting. Clinicians said that parents lose a sense of themselves in all facets of personal and social interactions:

I think that a lot of parents feel completely helpless and hopeless about what to do. After a while they know that anorexia is getting them to do things but sometimes their child sounds so believable that they don't know what to believe and then what to do; it almost incapacitates them to take action. (Kristie)

\section{Shame}

Clinicians spoke about parents' sense of being judged by others, which reinforced a sense of shame. Self-perceived failure was seen to lead to parental isolation:

Well it is, isn't it, shame on display. You walk around with a skeletal child and it's like, it's out there. There are lots of things that go on in households that families may well choose to cover up. You can't cover this one up, it's out there. (Jane)

\section{Insights into parents' sense of self}

Clinicians spoke about how parents conceptualized parenting a child with AN and how those meanings shaped the treatment process. Three subthemes emerged.

\section{Questioning themselves}

In their search for meaning, clinicians saw parents questioning their intrinsic beliefs about themselves as parents and their potency to help their child, often measuring themselves against an ideal of what being a parent involves:

I think that it really attacks a sense of their self and certainly their sense of their role as a parent. They really question themselves like what they've done and what they haven't done, how they might have played a role in the development of this eating disorder by not noticing it earlier and doing something about it then. (Monica)

\section{Loss}

Clinicians spoke about different types of loss that parents experience. Parents can lose their relationship with their child, or with the child they once had or with others within and outside the family. It can be a loss of the lifestyle they used to know: 
... for some parents it means that they've almost lost their child to something else and that their child isn't there anymore. They're a completely different person in that they've kind of lost them. (Jessica)

... it changes parents' lifestyle. It can interrupt people's work and their family life, their relationship with their other children. So its meaning is about the complete disruption to their life, loss of their dreams, their ambitions, and their whole way of living. (Louise)

\section{Meaning of recovery}

Some clinicians identified cases where helping the child recover from AN strengthened relationships and built unity as families work through the process of recovery:

I think a lot of parents have found a way to come together as a family. They've found meaning in supporting each other, meaning in connecting again, and for them, it's been about them being able to find a sense of being a parent again because that changed for various reasons over time and they've found strength within it. (Carla)

\section{Discussion}

Based on their experiences with families undergoing treatment, clinicians emphasized the emotional demands in parenting an adolescent with AN. Parents were viewed as vulnerable and despairing, often carrying feelings of guilt, shame, powerlessness, uncertainty, and loss. Whilst clinicians recognized that treatment can literally be a lifeline and that parents are often relieved to be playing a central role in their child's recovery, they also explained how treatment magnifies and augments the demands of AN for parents until the child has recovered. Many families find it difficult to cope with their responsibilities in the treatment regime whilst also managing their other family and employment demands.

The survey results suggest that clinicians providing family-based therapy for adolescent AN in this service support similar principles and aspects of treatment regardless of whether or not they reported using the Maudsley Family Based Treatment approach. Clinicians placed high value on principles underlying Maudsley, such as engaging and building relationships with parents, involving parents in the treatment process, and building parents' capacities through the provision of information, support and guidance. A staged approach to treatment, based loosely on the Maudsley stages, was advocated by clinicians across the service. The interviews revealed, however, that none of the clinicians who identified as implementing Maudsley provided treatment with strict adherence to the manual. They make case by case professional judgements on how adherence to components in the manual may jeopardize parents' engagement with treatment or could comprise a lack 
of responsiveness to parents' needs. Non-Maudsley clinicians, who utilized more generic family interventions, spoke in the interviews about how they integrated principles and practices from the Maudsley model into their systemic and narrative family based interventions. It was apparent that a Maudsley-type treatment approach was prevalent over a strict implementation of Maudsley. The findings indicated a professional culture of sharing and adapting knowledge for practice in the service.

Interviews with clinicians revealed a number of circumstances in which they supported the modification of Maudsley. This included when clinicians assessed that the existing demands on the family would prevent them from meeting the emotional and logistical requirements of the Maudsley treatment regime. In this case, components of the approach were skipped or regimes simplified. Clinicians also modified Maudsley when aspects of the model clashed with cultural or personal values within the family. Clinicians identified that Maudsley was not appropriate for Australian Aboriginal families, where a more flexible approach that challenges the White value system and is responsive to kinship systems and traditional practices was instead invoked. Lack of patient progress through the Maudsley treatment process also resulted in modifications to the model. In these cases clinicians reported using critical reflection skills and their breadth of professional training to identify alternative approaches that they felt were better suited to the circumstances of the adolescent and their family. Finally, the Maudsley approach was avoided in circumstances where there was potential for aspects of the treatment to reinforce abusive or dominating patterns of behavior within the family relationships. Again, this decision relied on the clinicians' professional assessments of family dynamics and their knowledge of alternative treatment approaches.

Modifying standardized treatments in this way reduces the fidelity of what is perceived to be evidence-based practice. Clinicians spoke about how their employing organization valued evidence-based treatments and as a consequence undervalued the professional assessments and judgements of clinicians. Clinicians too gained a degree of confidence from the evidence base of the Maudsley approach, but questioned the suitability of all aspects of the approach for all families. Clinicians willingly described themselves as adapting or enhancing Maudsley on the basis of family circumstances and professional judgements, and no one expressed concern that this reduced the fidelity of Maudsley. Clinical judgements can be viewed as a delicate balancing act where evidence for the intervention is weighed against the capacity to engage and keep the family in treatment through responding to their particular needs, values and desires. $\mathrm{AN}$ is, however, a dire mental illness. If Maudsley is genuinely the best treatment to avert starvation, then family compliance is of the highest priority. But if there are better alternatives for some families then it is important to engage in further research and generate evidence. The research reported here indicates that it would be worthwhile to examine adapted Maudsley-type treatment in comparison to the strict manualized 
version in order to address three questions: Are families better engaged and retained in treatment in comparison to a strict Maudsley approach? What are the wellbeing and recovery outcomes for adolescents? Are different versions of AN treatment appropriate in different circumstances?

The predominantly qualitative nature of this study and small sample size, drawn from four sites in a single organization, limits the strength of findings and potential relevance to other settings. Whilst training and supervision was provided to Maudsley clinicians by a specialist Maudsley treatment centre, distinct cultures of practice can develop in organizations. The findings have, however, identified circumstances in which alternatives to a dominant manualized treatment approach, Maudsley Family Based Treatment, warrant further consideration and testing. As clinicians emphasized in this study, understanding family values relies on building an empathic and trusting relationship between the clinician and family members. Manualized treatments cannot stand effectively alone, but instead rely upon clinicians being able to establish and maintain positive, empathic and constructive therapeutic relationships with families. It is on the basis of these relationships that parents engage with clinicians as active partners in the treatment of AN.

\section{References}

Aarons, G., \& Palinkas, L. (2007). Implementation of evidence-based practice in child welfare: Service provider perspectives. Administration and Policy in Mental Health and Mental Health Services Research, 34, 411-419. doi:10.1007/s10488-007-0121-3

Bulik, C. M., Berkman, N. D., Brownley, K. A., Sedway, J. A., \& Lohr, K. N. (2007). Anorexia nervosa treatment: A systematic review of randomized controlled trials. International Journal of Eating Disorders, 40, 310-320. doi:10.1002/(ISSN)1098-108X

Cook-Darzens, S., Doyen, C., \& Mouren, M. C. (2008). Family therapy in the treatment of adolescent anorexia nervosa: Current research evidence and its therapeutic implications. Eating and Weight Disorders, 13, 157-170. doi:10.1007/BF03327502

Cottee-Lane, D., Pistrang, N., \& Bryant-Waugh, R. (2004). Childhood onset anorexia nervosa: The experience of parents. European Eating Disorders Review, 12, 169-177. doi:10.1002/ (ISSN)1099-0968

Eisler, I. (2005). The empirical and theoretical base of family therapy and multiple family day therapy for adolescent anorexia nervosa. Journal of Family Therapy, 27, 104-131. doi:10.1111/joft.2005.27.issue-2

Eisler, I., Dare, C., Hodes, M., Russell, G. F. M., Dodge, E., \& Le Grange, D. (2000). Family therapy for adolescent anorexia nervosa: The results of a controlled comparison of two family interventions. Journal of Child Psychology and Psychiatry, 41, 727-736. doi:10.1111/jcpp.2000.41.issue-6

Fisher, C., Hetrick, S. E., \& Rushford, N. (2010). Family therapy for anorexia nervosa. Cochrane Database of Systematic Reviews, 4, CD004780. doi:10.1002/14651858. CD004780.pub2

Gowers, S. G., Clark, A., Roberts, C., Griffiths, A., Edwards, V., Bryan, C., ... Barrett, B. (2007). Clinical effectiveness of treatments for anorexia nervosa in adolescents. British Journal of Psychiatry, 91, 427-435. doi:10.1192/bjp.bp.107.036764 
Keel, P., \& Haedt, A. (2008). Evidence-based psychosocial treatments for eating problems and eating disorders. Journal of Clinical Child and Adolescent Psychology, 37, 39-61. doi:10.1080/15374410701817832

Krautter, T., \& Lock, J. (2004). Is manualized family-based treatment for adolescent anorexia nervosa acceptable to patients? Patient satisfaction at the end of treatment. Journal of Family Therapy, 26, 66-82. doi:10.1111/j.1467-6427.2004.00267.x

Le Grange, D., \& Lock, J. (2005). Family-based treatment of adolescent anorexia nervosa: The Maudsley Approach. Toronto, Canada: National Eating Disorder Information Centre

Lock, J. (2011). Evaluation of family treatment models for eating disorders. Current Opinion in Psychiatry, 24, 274-279. doi:10.1097/.0b013e328346f71e

Lock, J., Agras, S., Bryson, S., \& Kraemer, H. C. (2005). A comparison of short-and long-term family therapy for adolescent anorexia nervosa. Journal American Academy of Child and Adolescent Psychiatry, 44, 632-639. doi:10.1097/01.chi.0000161647.82775.0a

Lock, J., Couturier, J., Bryson, S., \& Agras, S. (2006). Predictors of dropout and remission in family therapy for adolescent anorexia nervosa in a randomized clinical trial. International Journal of Eating Disorders, 39, 639-647. doi:10.1002/ (ISSN) 1098-108X

Lock, J., \& Le Grange, D. (2013). Treatment manual for anorexia nervosa (2nd ed.). New York, NY: Guilford Press.

Ma, J. (2011). An exploratory study of the impact of an adolescent's eating disorder on Chinese parents' well-being, marital life and perceived family functioning in Shenzhen, China: Implications for social work practice. Child and Family Social Work, 16, 33-42. doi:10.1111/j.1365-2206.2010.00703.x

Marshall, C., \& Rossman, G. (2006). Designing qualitative research (4th ed.). Thousand Oaks, CA: Sage.

Rhodes, P., Baillee, A., Brown, J., \& Madden, S. (2008). Can parent-to-parent consultation improve the effectiveness of the Maudsley model of family-based treatment for anorexia nervosa? A randomised control trial. Journal of Family Therapy, 30, 96-108. doi:10.1111/ j.1467-6427.2008.00418.x

Rhodes, P., Brown, J., Baillee, A., \& Madden, S. (2005). Parental efficacy in the family-based treatment of anorexia: Preliminary development of the Parents Versus Anorexia Scale (PVA). European Eating Disorders Review, 13, 392-405. doi:10.1002/erv.658

Smith, J. A., Flowers, P., \& Larkin, M. (2009). Interpretative phenomenological analysis: Theory, method and research. Los Angeles, CA: Sage

Stillar, A., Strahan, E., Nash, P., Files, N., Scarborough, J., Mayman, S., ... Robinson, A. L. (2016). The influence of carer fear and self-blame when supporting a loved one with an eating disorder. Eating Disorders, 24, 173-185. doi:10.1080/10640266.2015.1133210

Szmukler, G. I., Eisler, I., Russell, G., \& Dare, C. (1985). Anorexia nervosa, parental expressed emotion, and dropping out of treatment. British Journal of Psychiatry, 147, 265-271. doi:10.1192/bjp.147.3.265

Treasure, J., Sepulveda, A. R., Whitaker, W., Todd, G., Lopez, C., \& Whitney, J. (2007). Collaborative care between professionals and non-professionals in the management of eating disorders: A description of workshops focused on interpersonal maintaining factors. European Eating Disorders Review, 15, 24-34. doi:10.1002/erv.758

Zabala, M. J., MacDonald, P., \& Treasure, J. (2009). Appraisal of caregiving burden, expressed emotion and psychological distress in families of people with eating disorders: A systematic review. European Eating Disorders Review, 17, 338-349. doi:10.1002/erv.v17:5 